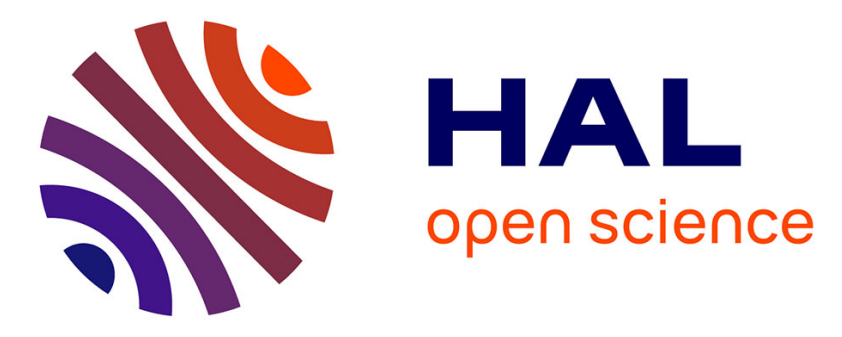

\title{
Novel Ni-La-hydrotalcite derived catalysts for CO2 methanation
}

Dominik Wierzbicki, Radoslaw Debek, Monika Motak, Teresa Grzybek, Maria Elena Gálvez, Patrick da Costa

\section{- To cite this version:}

Dominik Wierzbicki, Radoslaw Debek, Monika Motak, Teresa Grzybek, Maria Elena Gálvez, et al.. Novel Ni-La-hydrotalcite derived catalysts for CO2 methanation. Catalysis Communications, 2016, 83, pp.5-8. 10.1016/j.catcom.2016.04.021 . hal-01318308

\section{HAL Id: hal-01318308 https://hal.sorbonne-universite.fr/hal-01318308}

Submitted on 19 May 2016

HAL is a multi-disciplinary open access archive for the deposit and dissemination of scientific research documents, whether they are published or not. The documents may come from teaching and research institutions in France or abroad, or from public or private research centers.
L'archive ouverte pluridisciplinaire HAL, est destinée au dépôt et à la diffusion de documents scientifiques de niveau recherche, publiés ou non, émanant des établissements d'enseignement et de recherche français ou étrangers, des laboratoires publics ou privés. 


\title{
Novel Ni-La-Hydrotalcite derived catalysts for $\mathrm{CO}_{2}$ methanation
}

Dominik Wierzbicki ${ }^{\mathrm{a}}$, Radosław Debek ${ }^{\mathrm{a}, \mathrm{b}}$, Monika Motak $^{\mathrm{a}}$, Teresa Grzybek ${ }^{\mathrm{a}}$, Maria Elena Gálvez ${ }^{\mathrm{b}}$,

$$
\text { Patrick Da Costa }{ }^{\mathrm{b}} *
$$

${ }^{a}$ AGH University of Science and Technology, Faculty of Energy and Fuels, Al. A. Mickiewicza 30, 30-059 Cracow, Poland

b Sorbonne Universités, UPMC, Univ. Paris 6, CNRS, UMR 7190, Institut Jean Le Rond d'Alembert, 2 place de la gare de ceinture, 78210 Saint-Cyr-L'Ecole, France

*Corresponding author. Tel: +33-1-30854865; fax: + 33-1-30854899, patrick.da_costa@upmc.fr

\begin{abstract}
A series of hydrotalcite-derived mixed oxides containing $\mathrm{Ni} / \mathrm{Mg} / \mathrm{La} / \mathrm{Al}$ obtained by thermal decomposition were characterized by $\mathrm{XRD}, \mathrm{CO}_{2}$-TPD and $\mathrm{H}_{2}$-TPR. The results confirm the formation of periclase-like materials, and the addition of lanthanum resulted in the formation of a separate phase. The incorporation of $2 \mathrm{wt} . \%$ of lanthanum leads to an increase of the catalytic performance at temperatures from 250 to $300^{\circ} \mathrm{C}$ with $\mathrm{CO}_{2}$ conversion of $46.5-75 \%$ and $\mathrm{CH}_{4}$ selectivity of $99-98 \%$. The activity is directly connected with basicity that increases with the incorporation of La into the HT-derived catalysts.
\end{abstract}

Keywords: $\mathrm{CO}_{2}$ methanation, hydrotalcite, nickel, Lanthanum 


\section{Introduction}

The $\mathrm{CO}_{2}$ concentration increase in atmosphere, which is considered to be one of the anthropogenic causes of global warming, has led to renewed interest in $\mathrm{CO}_{2}$ hydrogenation (Sabatier reaction). This process offers the possibility of storing off-peak renewable energy, i.e. in the form of water-electrolysis hydrogen, and, at the same time, treating $\mathrm{CO}_{2}$ as raw material, to produce storable and transportable fuels (methane), or other commodities [1]. This way of producing of gaseous and/or liquid fuels may become an effective method of stabilizing $\mathrm{CO}_{2}$ emissions, in a global zero-emission closed cycle.

Catalytic $\mathrm{CO}_{2}$ methanation has been deeply studied using catalysts containing group VIIIB metals (Fe, Ru, Co, Rh, Ir, Ni, Pd, Pt) on different supports $\left(\mathrm{Al}_{2} \mathrm{O}_{3}, \mathrm{SiO}_{2}, \mathrm{ZrO}_{2}, \mathrm{CeO}_{2}\right.$, mixed oxides of $\mathrm{Ce}-\mathrm{Zr}$ and $\mathrm{TiO}_{2}$ ) [2]. The catalytic systems containing $\mathrm{Ni}, \mathrm{Ru}$ and $\mathrm{Rh}$ were the most effective [3-6]. Though much cheaper than $\mathrm{Ru}$ and $\mathrm{Rh}$, Ni-based catalysts suffer from deactivation at low temperatures due to the strong interaction of $\mathrm{Ni}$ with $\mathrm{CO}$ and the formation of mobile carbonyls, which leads to the sintering of the active phase $[7,8]$. The choice of the support is furthermore important since it may determine the adsorptive properties of the catalytic system and the interaction support-active phase [2]. Acid-basic properties of oxides derived from hydrotalcites (HT) can be tailored for specific catalytic applications such as for $\mathrm{CO}_{2}$ valorization through dry reforming [9]. However, to date few publications deal with $\mathrm{CO}_{2}$ methanation over HT-derived catalysts [10, 11]. Gabrovska et al. [10] studied co-precipitated NiAl-HT-based materials with different content of nickel $(21,32$ and $42 \mathrm{wt} . \%$ ) in which the catalytic activity strongly depended on $\mathrm{Ni}$ content, reduction and reaction temperatures. He et al. [11] reported that well-dispersed and stable nickel particles could be obtained through the decomposition of Ni-containing HTs, and claimed that this fact together with the existence of strong basic sites resulted in enhanced methanation activity. 
It is nowadays well known that lanthanum can modify the redox properties of a catalytic material. In fact, the incorporation of lanthanum into Ni-containing HT-derived catalysts led to a beneficial effect on the nickel dispersion, catalytic activity and suppressed the formation of carbon in dry methane reforming [9]. However, there is no information in the existing literature dealing with the influence of the presence of La in HT-derived catalysts for $\mathrm{CO}_{2}$ methanation. The aim of this work is thus to study the properties and activity of modified hydrotalcite-like materials containing $\mathrm{Ni}, \mathrm{La}, \mathrm{Al}$ and $\mathrm{Mg}$ as prospective catalysts for $\mathrm{CO}_{2}$ methanation, with low Ni loadings.

\section{Experimental}

\subsection{Synthesis of the materials}

Hydrotalcites containing M(III) trivalent and M(II) divalent metals ( $\mathrm{Al}, \mathrm{La}, \mathrm{Mg}, \mathrm{Ni}$,) with $\mathrm{M}(\mathrm{III}) /(\mathrm{M}(\mathrm{III})+\mathrm{M}(\mathrm{II}))$ molar ratio of 0.25 , (Table 1), were prepared through a co-precipitation method at constant $\mathrm{pH}$ (from 9.5 to 10). Two aqueous solutions, of respectively the mixed nitrates of the divalent and trivalent metals and of sodium hydroxide $(1 \mathrm{M})$, were added dropwise into a flask containing an aqueous solution of sodium carbonate, under vigorous stirring at $65^{\circ} \mathrm{C}$ and constant $\mathrm{pH}$. The mixture was aged for $24 \mathrm{~h}$ at $50^{\circ} \mathrm{C}$, then filtered, washed with deionized water and dried at $80^{\circ} \mathrm{C}$ overnight. The obtained materials were finally calcined at $550^{\circ} \mathrm{C}$ for $5 \mathrm{~h}$. The nominal (assumed) concentration of the components is listed in Table 1.

\subsection{Physico-chemical characterization}

The HT-derived catalysts were characterized by XRD, TPR and TPD-CO 2 XRD measurements were carried out using PANalytical-Empyrean diffractometer, equipped with $\mathrm{CuK}_{\alpha}(\lambda=1.5406 \AA \hat{)})$ radiation source, within $2 \theta$ range from 3 to $90^{\circ}$, (step-size $\left.=0.02^{\circ} / \mathrm{min}\right) . \mathrm{Ni}$ 
crystallite sizes were calculated for the catalysts after reduction and reaction using the Scherrer equation. Temperature programmed reduction $\left(\mathrm{H}_{2}-\mathrm{TPR}\right)$ profiles were obtained using BELCAT-M (BEL Japan) apparatus equipped with a thermal conductivity detector (TCD). The calcined materials were first outgassed at $100^{\circ} \mathrm{C}$ for $2 \mathrm{~h}$ and then reduced using $5 \% \mathrm{H}_{2} / \mathrm{Ar}$ at the heating rate of $7.5^{\circ} \mathrm{C} / \mathrm{min}$ from $100{ }^{\circ} \mathrm{C}$ to $900{ }^{\circ} \mathrm{C}$. For each measurement a sample of $60 \mathrm{mg}$ was taken. $\mathrm{CO}_{2}$ Temperature programmed desorption $\left(\mathrm{CO}_{2}\right.$-TPD) was performed on the same device. The materials were degassed for $2 \mathrm{~h}$ at $500^{\circ} \mathrm{C}$ and then cooled to $80^{\circ} \mathrm{C}$. Subsequently a mixture of $10 \% \mathrm{CO}_{2} / \mathrm{He}$ was fed for $1 \mathrm{~h}$ in order to adsorb $\mathrm{CO}_{2}$, followed by desorption of weakly adsorbed $\mathrm{CO}_{2}$ using a flow of $\mathrm{He}$ for 15 minutes. In order to measure the evolution of $\mathrm{CO}_{2}$, the material was heated up under $\mathrm{He}$ flow at $10^{\circ} \mathrm{C} / \mathrm{min}$ from $80^{\circ} \mathrm{C}$ to $900^{\circ} \mathrm{C}$. The concentration of evolved $\mathrm{CO}_{2}$ was measured with a TCD detector.

\section{3. $\mathrm{CO}_{2}$ hydrogenation experiments}

$\mathrm{CO}_{2}$ methanation was studied in a tubular quartz reactor heated by an electric furnace. Temperature was measured and controlled inside the catalytic bed with the aid of a K-type thermocouple. A reactant flow of $100 \mathrm{ml} / \mathrm{min}\left(\mathrm{GHSV}=12,000 \mathrm{~h}^{-1}\right)$ containing $\mathrm{H}_{2} / \mathrm{CO}_{2} / \mathrm{Ar}=$ $12 / 3 / 5$ was sent to the reactor. The products were analyzed using an on-line Varian GC4900 micro-chromatograph equipped with a TCD detector. Prior to the reaction the catalysts were reduced in situ at $900^{\circ} \mathrm{C}$ for $1 \mathrm{~h}$ under $10 \% \mathrm{H}_{2} / \mathrm{Ar}$. The catalytic activity was then determined from 250 to $450^{\circ} \mathrm{C}$. At each temperature the sample was kept for 30 minutes in steady-state operation.

\section{Results and discussion}

\subsection{From the hydrotalcite precursors to the mixed oxides derived materials}

Figure 1 shows the diffractograms acquired for the fresh hydrotalcite (a), the hydrotalcitederived catalyst (NiLa4-HT) obtained upon calcination (b), the reduced (c) and the spent (d) 
HT-derived catalyst. The patterns obtained for fresh HT show the typical reflections of layered-structured hydrotalcites [13]. In the case of the HT containing higher amounts of lanthanum, i.e. NiLa4-HT and NiLa2-HT (not shown), separate phases arising from $\mathrm{La}_{2}\left(\mathrm{CO}_{3}\right)_{2}(\mathrm{OH})_{2}$ and $\mathrm{La}_{2} \mathrm{O}_{2} \mathrm{CO}_{3}$ were as well observed. Upon calcination, XRD patterns evidence the typical reflections of a periclase-like structure at $2 \theta=35.3,43.5$ and $63^{\circ}$. Lanthanum carbonates are as well observed as a separate phase, as well as $\mathrm{La}_{2} \mathrm{O}_{3}$. The reflections corresponding to this isolated lanthanum carbonate phase disappear for the catalysts submitted to reduction in $10 \% \mathrm{H}_{2} /$ Ar. These patterns reveal the existence of a metallic Ni phase. The crystal sizes for such Ni particles are in the range 8-9 nm, see Table 2, similar to those reported in the existing literature for Ni-containing HT-derived catalyst [14]. Crystal sizes remained practically unchanged in the catalysts employed in the methanation reaction, i.e. 8-10 $\mathrm{nm}$ crystal size calculated for the spent catalysts.

\subsection{Basicity and active sites}

Fig. 2 contains the $\mathrm{CO}_{2}$-TPD profiles acquired for the different HT-derived catalysts after reduction under $10 \% \mathrm{H}_{2} / \mathrm{Ar}$. TPD profiles were deconvoluted into three Gaussian peaks, corresponding to weak $\left(138-150^{\circ} \mathrm{C}\right)$, medium strength $\left(232-251^{\circ} \mathrm{C}\right)$ and strong $\left(349-374^{\circ} \mathrm{C}\right)$ basic sites, as shown in Table 2. Low strength basic sites correspond to surface $\mathrm{OH}^{-}$, medium to Lewis acid-base pairings and strong arise from low-coordination surface $\mathrm{O}^{2-}$ [15].

Though the incorporation of only 1 wt.\% of lanthanum leads to a slight decrease in total basicity, the amount of basic sites, i.e. sites able to chemisorb $\mathrm{CO}_{2}$, generally increases upon La-loading. Moreover, from peak deconvolution it seems that medium strength basic sites are more present in the La-doped HT-derived catalysts, i.e. its concentration increases from 60 $\mu \mathrm{mol} / \mathrm{g}$ for $\mathrm{Ni}-\mathrm{HT}$ to $113 \mu \mathrm{mol} / \mathrm{g}$ and to $87 \mu \mathrm{mol} / \mathrm{g}$, for the catalysts respectively containing 2 and 4 wt.\% of La. Let us remark here that the differences between basicity for Ni-HT's containing 1 wt. $\%$ and 2,4 wt.\% of La might be as well caused by a partial blocking of the 
basic sites in the mixed oxide hydrotalcite-derived material, upon the introduction of low amounts of lanthanum and its compensation through the formation of new basic sites after incorporation of 2 and $4 \mathrm{wt} \%$ of La.

Fig. 3 shows the $\mathrm{H}_{2}$-TPR profiles for the calcined HT-derived catalysts. They all exhibit one wide asymmetric peak arising from the reduction of nickel oxide species to metallic $\mathrm{Ni}^{\circ}$ $\left(814-846^{\circ} \mathrm{C}\right)$. This higher reduction temperatures vis-à-vis the much lower temperatures expected for the oxidation of either bulk $\mathrm{NiO}$ or dispersed $\mathrm{NiO}$ crystallites points to the existence of a thermally stable phase of $\mathrm{Mg}(\mathrm{Ni}, \mathrm{Al}) \mathrm{O}$ in the form of a solid solution of mixed oxides, and thus to a very strong interaction between the nickel species and the $\mathrm{Al}-\mathrm{Mg}$ hydrotalcite matrix $[9,16]$. The addition of La visibly shifts the reduction of Ni-species to lower temperatures, i.e. from $846^{\circ} \mathrm{C}$ for Ni-HT to $814-821^{\circ} \mathrm{C}$ for NiLa1-HT and NiLa4-HT, respectively. Additionally, a shoulder appears at ca. $690^{\circ} \mathrm{C}$ for NiLa2-HT and NiLa4-HT (2 and 4 wt.\% of La, respectively), which can be assigned to isolated and more weakly bonded $\mathrm{NiO}$ species. Moreover, for NiLa2-HT an additional weak peak can be as well observed at temperatures ca. 400 and $490^{\circ} \mathrm{C}$ that may correspond to bigger bulk $\mathrm{NiO}$ crystallites. Lucredio et al. [17] showed that low amounts of lanthanum resulted in further stabilization of the Niphase and thus increased reduction temperatures, at higher La-loadings, however, TPR reduction temperature decreased, pointing to weakened interaction between $\mathrm{Ni}$-species and the hydrotalcite matrix [18]. Nickel-containing materials obtained upon calcination of hydrotalcites form homogenous mixed oxides (periclase structure), where $\mathrm{NiO}$ and $\mathrm{MgO}$ interactions are very strong, resulting in the need of harsh reduction conditions, in contrast to $\mathrm{Ni}$ impregnated supports, where the nickel is more likely to be deposited on the surface, and then the reducibility may be expected to be much higher than for hydrotalcite systems. The obtained $\mathrm{H}_{2}$-TPR results are in good agreement with literature reports [11]. 


\subsection{Catalytic activity towards $\mathrm{CO}_{2}$ hydrogenation}

The $\mathrm{CO}_{2}$ conversion measured during the methanation experiments is plotted in Fig. 4, for the different HT-derived catalysts and as a function of reaction temperature. The thicker continuous line represents the $\mathrm{CO}_{2}$ conversion forecasted by the thermodynamic equilibrium for this reaction. Thermodynamics predicts complete $\mathrm{CO}_{2}$ conversion at low reaction temperatures, decreasing with increasing temperature, since the other routes start to be favored, such as all the set of reforming reactions, resulting in the formation of undesirable side-products such as $\mathrm{CO}$. At $250^{\circ} \mathrm{C}$, the $\mathrm{CO}_{2}$ conversions measured in the presence of the different HT-derived catalysts are still far away from the maximal thermodynamic conversion limit. The highest conversions are obtained for the catalysts containing 2 and 4 wt.\% of lanthanum, i.e. $46.5 \%$ and $46 \%$ for NiLa2-HT and NiLa4-HT, respectively. Activity towards $\mathrm{CO}_{2}$ methanation is thus promoted in the presence of $\mathrm{La}$, as a consequence of increased basicity, concretely in terms of medium strength basic sites, and looser interaction of $\mathrm{Ni}$ species and the Al-Mg hydrotalcite matrix, resulting in enhanced reducibility. Indeed, the difference in catalytic activity is in good agreement with much higher basicity shown for catalysts containing 2 and 4 wt.\% of La. As observed by XRD, La forms separate phases and is not introduced into the hydrotalcite structure. Therefore, the changes in basicity are a consequence of two opposing effects: partial blockage of hydrotalcites basic sites by lanthanum oxide and the introduction of new basic sites by the latter. For the catalyst with $1 \%$ La, the decrease of hydrotalcite basic sites could not be compensated (due to low amount of new added basic sites), in contrast to HTLa2 and HTLa4, where the overall effect was positive. As reported by Pan et al. [19] the reaction of $\mathrm{CO}_{2}$ methanation on nickel containing catalysts involves (i) $\mathrm{H}_{2}$ dissociative adsorption on metallic nickel and (ii) $\mathrm{CO}_{2}$ adsorption on basic sites, thus making it necessary to find an optimum composition of the catalysts. Pan et al. also suggested that the presence of medium strength basic sites resulted in improved 
catalytic activity due to the promoted formation of monodentate formate species, which is an active intermediate in methane formation. However, as reaction temperature increases $\mathrm{CO}_{2}$ conversion converges to similar values independently of the HT-derived catalysts used. At temperatures higher than $400^{\circ} \mathrm{C}$, methanation and its side-reactions become temperaturepromoted and the intrinsic features of each catalyst leading to improved performance at lower temperatures are no longer that important. Moreover, at temperatures higher than $400^{\circ} \mathrm{C}$, a loss in reaction selectivity can be expected. The selectivity towards methane production measured for the different catalysts during the activity tests is plotted in Fig. 5 as a function of temperature. In the low temperature range almost complete selectivity to methane was measured for all the catalysts tested, i.e. 98 to ca. $99 \%$ at $250^{\circ} \mathrm{C}$. As expected, selectivity slightly decreases with increasing temperature. As expected, selectivity slightly decreases with increasing temperature for samples Ni15, Ni15La2 and Ni15La4, while for the Ni15La1 sample the selectivity towards methane increased from $400^{\circ} \mathrm{C}$ to $450^{\circ} \mathrm{C}$, which is in the range of experimental error. No other product except $\mathrm{CO}$ and $\mathrm{CH}_{4}$ were registered. The selectivities to $\mathrm{CO}$ were between ca. 1 and $3 \%$ (3\% for the most active $\mathrm{Ni} 15 \mathrm{La} 2$ at $450^{\circ} \mathrm{C}$ ). The amounts of registered $\mathrm{CO}$ are relatively low, it is rather difficult to discuss a relationship between the selectivity and basicity, or any other property of the studied catalysts. We can only roughly say that, a priori, the samples with the highest amount of basic sites (Ni15La2 and Ni15La4) show the highest and the lowest selectivity towards methane. Let us note here that the catalytic activity was found to remain completely stable after $5 \mathrm{~h}$ time on stream, without further evolution of basicity and no modification of Ni-crystal size on the spent catalysts (Table 2). 


\section{Conclusions}

La-promoted Ni-Mg-Al hydrotalcite-derived catalysts were prepared through coprecipitation, characterized and tested in the $\mathrm{CO}_{2}$ hydrogenation reaction. The introduction of La affected the $\mathrm{CO}_{2}$ adsorption capacity of the catalysts through the introduction of medium strength basic sites. The presence of La also influenced the interaction of Ni-species with the Mg-Al matrix. In HT-derived catalysts, Ni-species are found commonly in the form of mixed oxides solid solutions together with $\mathrm{Mg}$ and $\mathrm{Al}$ oxides. Lanthanum increases the reducibility of Ni-species by means of softening the interaction between them and the HT matrix. Both increased basicity, in terms of medium strength basic sites, and increased Ni-reducibility results in much higher activity at low temperatures for such La-promoted HT-derived catalysts.

\section{Acknowledgements}

R. Dębek, M. Motak and T. Grzybek would like to acknowledge AGH grant 11.11.210.213 and French Embassy in Poland.

\section{References}

[1] G. Centi, S. Perathoner, Catal.Today 148 (2009) 191-205

[2] W. Wang, J. Gong, Front. Chem. Sci. Eng. 5 (2011) 2-10

[3] E. Zağli, J. Falconer, J.Catal. 62 (1980) 280-285

[4] E. Zağli, J. Falconer, J.Catal. 69 (1981) 1-8

[5] G.D. Weatherbee, C.H. Bartholomew, J.Catal. 87 (1984) 352-362

[6] P. Panagiotopolou, D.I. Kondarides, X.R. Verykios, Appl.Catal. A: Gen. 344 (2008) 45-54 
[7] M.R. Prairie, A. Renken, J.G. Highfield, K. Ravindranathan Thampi, M. Grätzel, J.Catal. 129 (1991) 130-144

[8] P.W. Yesgar, M. Scheintuch, J. Catal. 127 (1991) 576-594

[9] A. Serrano-Lotina, L. Rodriguez, G. Munoz, L. Daza, J. Power Sources 196 (2011) 4404

[10] M. Gabrovska, R. Edreva-Kardijeva, D. Crisan, P. Tzvetkov, M. Shopska, I. Shtreva, React. Kinet; Mech. Catal. 105 (2012) 79

[11] L. He, Q. Lin, Y. Liu, Y. Huang, J. Energy Chem. 23 (2014) 587.

[12] F. Cavani, F. Trifiro, A. Vaccari, Catal.Today 11 (1991) 173.

[13] V. Rives, Mater.Chem.Phys. 75 (2002) 19.

[14] J. Zhang, N. Zhao, W. Wei, Y. Sun, Int. J. Hyd. En. 35 (2010) 11776-11786

[15] L.J.I. Coleman, W. Epling, P.R. Hudgins, E. Croiset, Appl. Catal. A: Gen. 363 (2009) $52-63$.

[16] R. Dębek, M. Radlik, M. Motak, M.E.Galvez, W. Turek, P. Da Costa, T. Grzybek, Catal.Today 257 (2015) 59-65

[17] A.F. Lucredio, J.M. Assaf, E. M. Assaf, Biomass Bioenergy 60 (2014) 8-17.

[18] A.F. Lucrédio, G. Jerkiewickz, E.M. Assaf, Appl.Catal. A: Gen. 333 (2007) 90-95

[19] Q.S. Pan, J.X. Peng, T.J. Sun, D.N. Gao, S. Wang, S.D. Wang, Fuel Process Technol. $123(2014) 166-171$ 


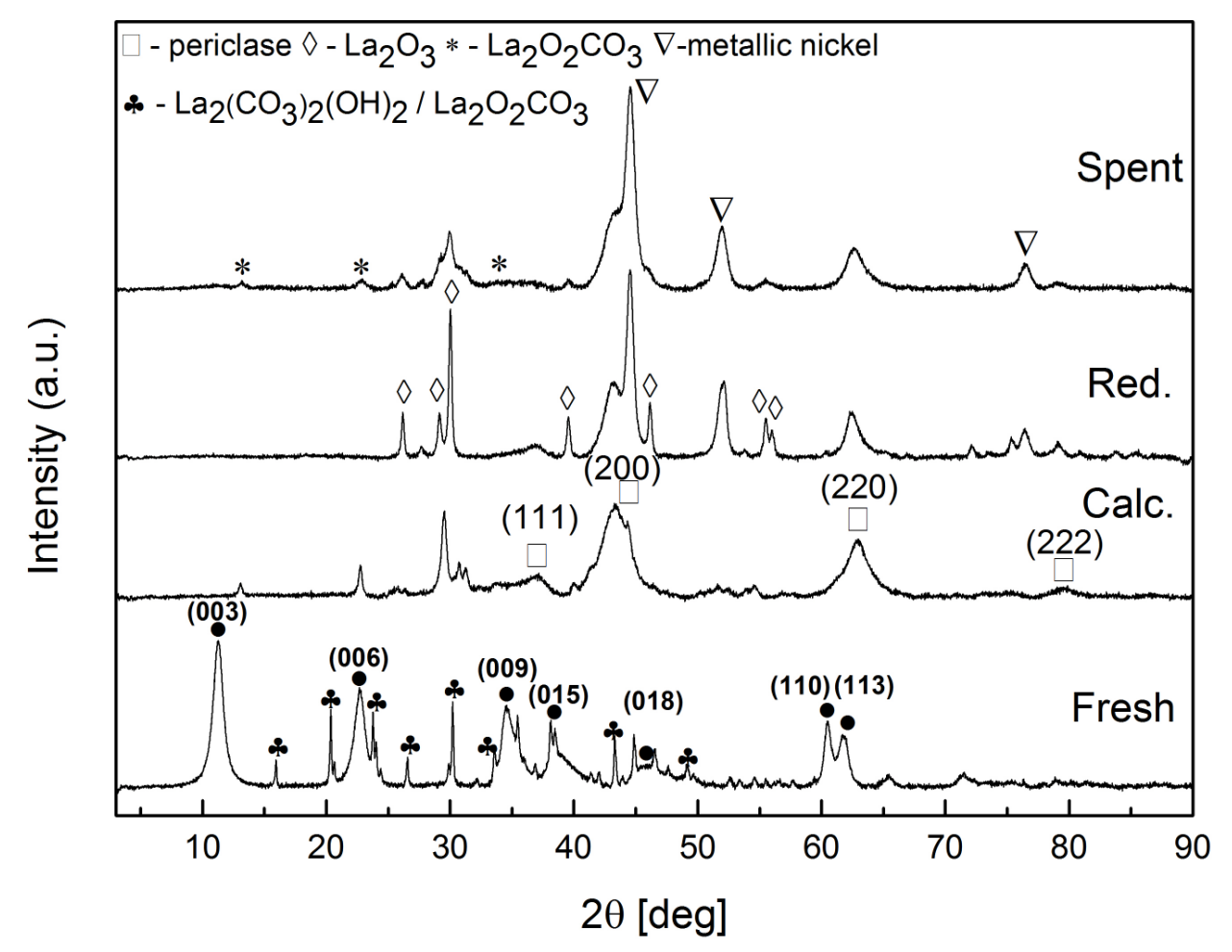

Figure 1. XRD patterns for NiLa4-HT (fresh, calcined, reduced and spent) 


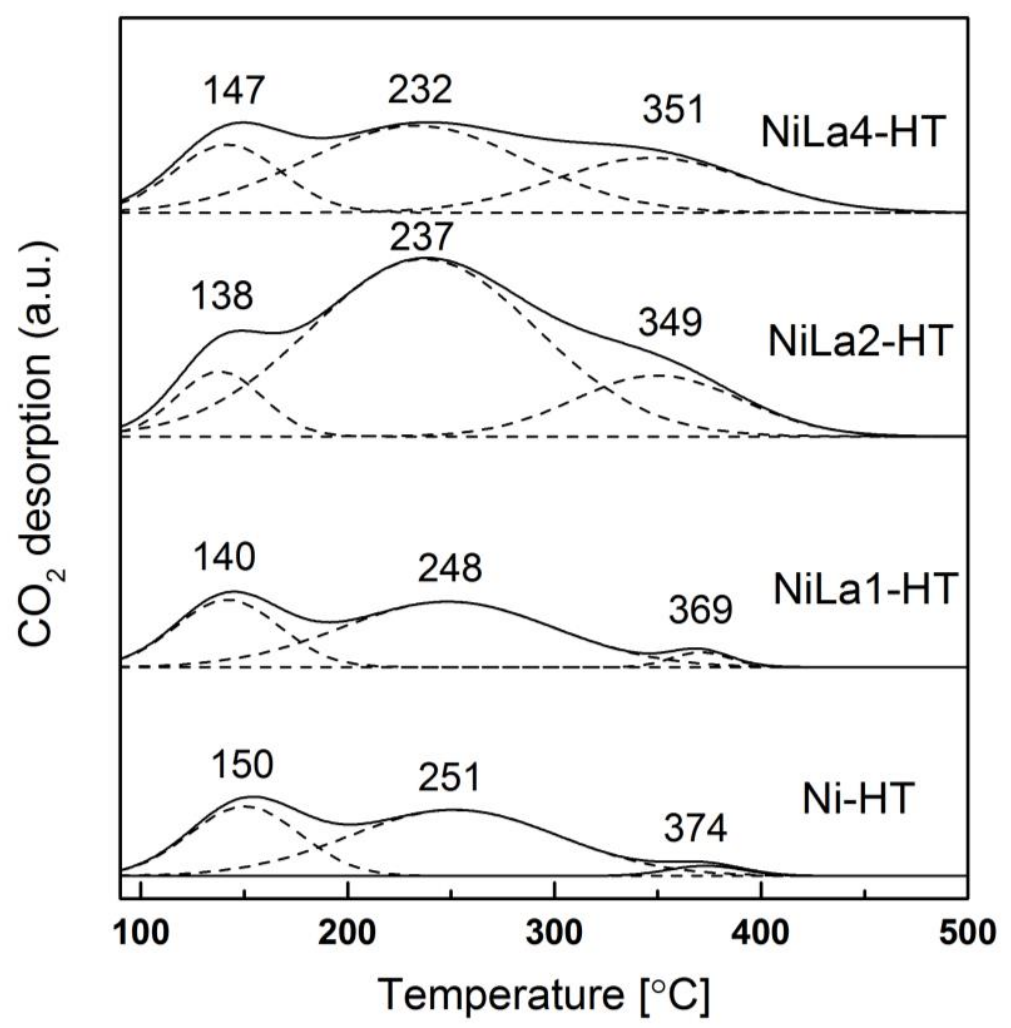

Figure 2. $\mathrm{CO}_{2}$-TPD profiles for the reduced HT-derived catalysts. 


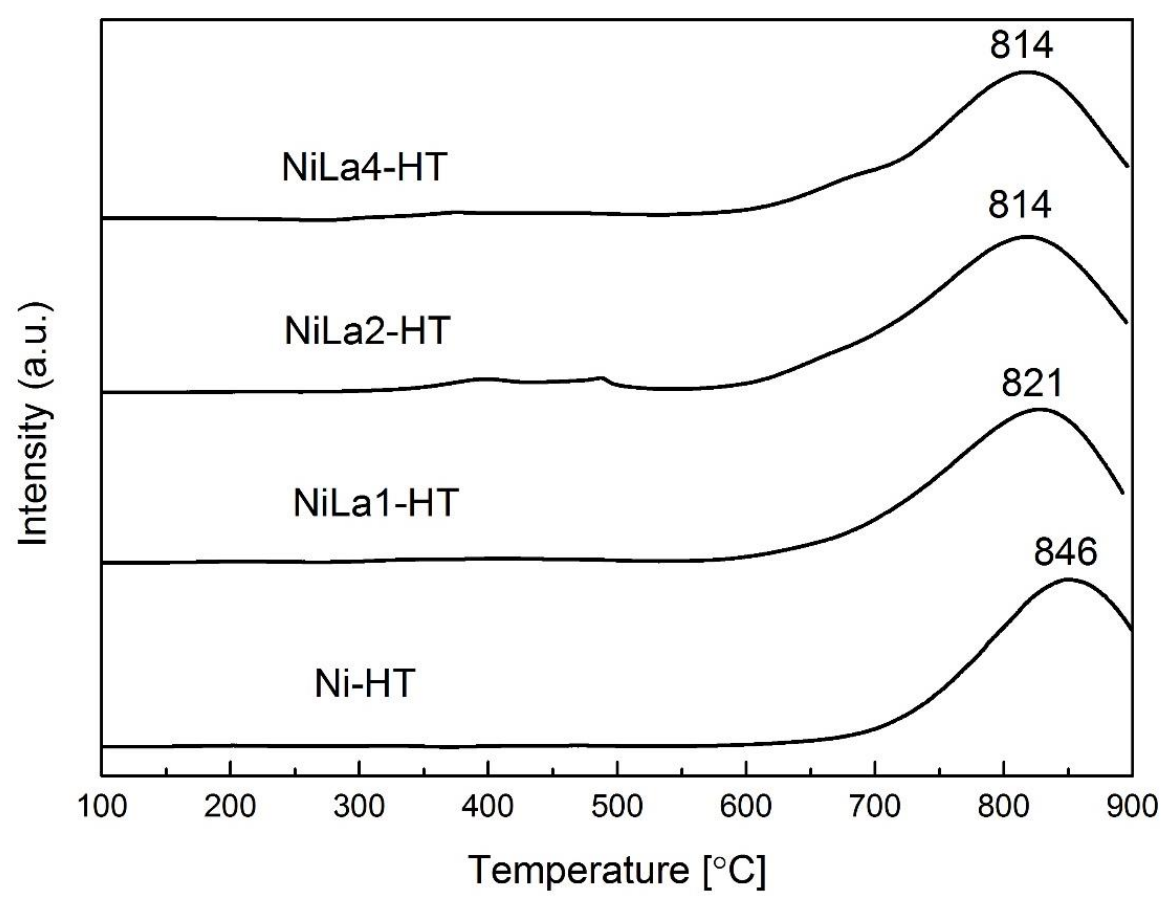

Figure 3. $\mathrm{H}_{2}$-TPR of mixed oxides 


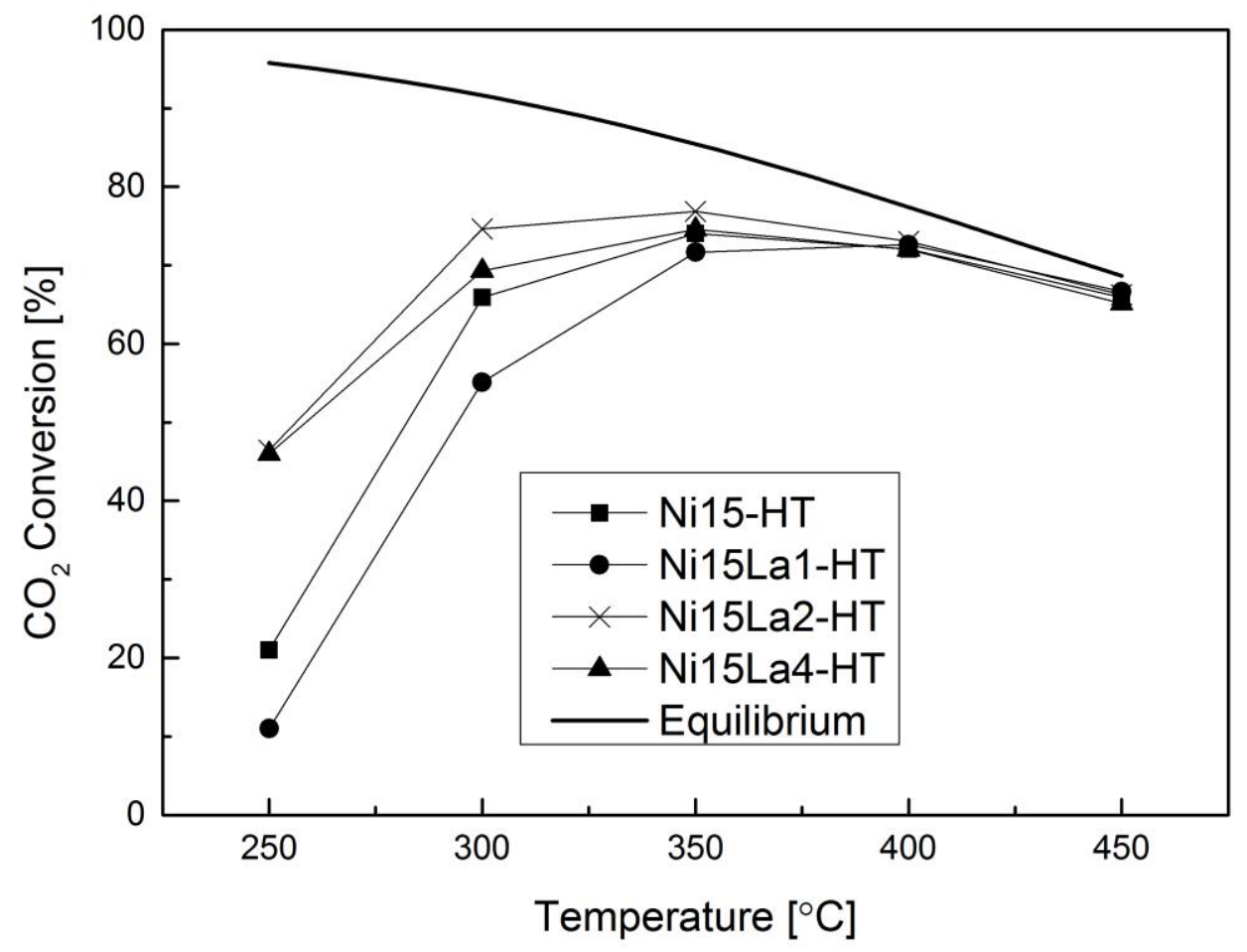

Figure 4. $\mathrm{CO}_{2}$ Conversion versus temperature for obtained mixed oxides 


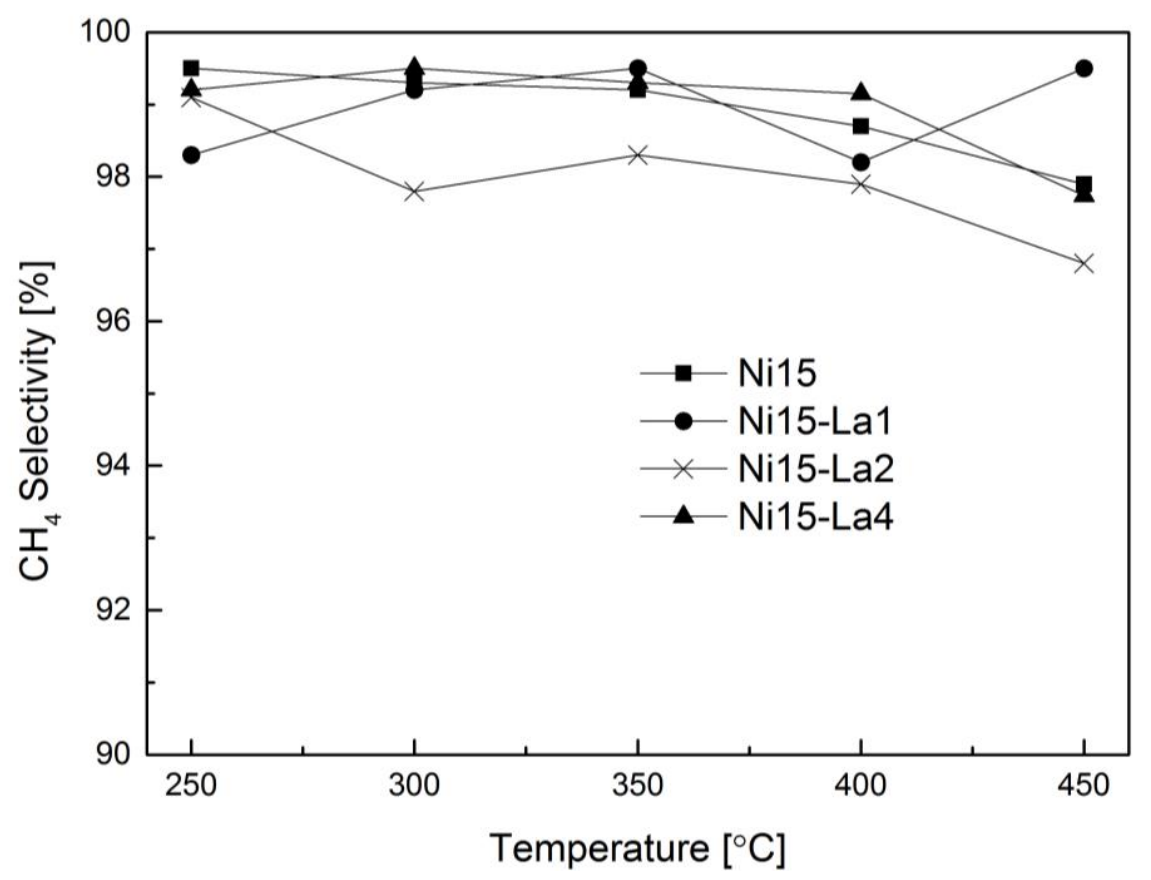

Figure 5. $\mathrm{CH}_{4}$ Selectivity versus temperature for obtained mixed oxides 
Table 1. Nominal concentration of trivalent and divalent cations in the prepared catalysts

\begin{tabular}{|c|c|c|c|c|c|c|}
\hline \multirow{3}{*}{ Catalysts } & \multicolumn{6}{|c|}{$\left[\mathrm{Me}_{\mathrm{y}} \mathrm{Mg}_{\mathrm{x}} \mathrm{Al}_{0.25}(\mathrm{OH})_{2}\right]\left(\mathrm{CO}_{3}{ }^{2-}\right)_{0.125^{*}} \mathrm{O.5H}_{2} \mathrm{O}$} \\
\hline & \multicolumn{4}{|c|}{ Metal content [wt.\%] } & \multirow{2}{*}{$\mathrm{La} / \mathrm{Al}$ ratio } & \multirow{2}{*}{$\frac{M(I I I)}{M(I I)+M(I I I)}$} \\
\hline & $\mathrm{Ni}$ & $\mathrm{La}$ & $\mathrm{Mg}$ & $\mathrm{Al}$ & & \\
\hline Ni-HT & 15 & - & 15.8 & 8.1 & - & 0.25 \\
\hline NiLa1-HT & 15 & 1 & 15.6 & 7.9 & 0.03 & 0.25 \\
\hline NiLa2-HT & 15 & 2 & 15.4 & 7.6 & 0.07 & 0.25 \\
\hline NiLa4-HT & 15 & 4 & 15.0 & 7.1 & 0.11 & 0.25 \\
\hline
\end{tabular}

Table 2. Crytallite size of $\mathrm{Ni}^{\circ}$ particles (measured by XRD) and basicity of different NiLa-HT samples (from $\mathrm{CO}_{2}$-TPD)

\begin{tabular}{|c|c|c|c|c|c|c|}
\hline \multirow{2}{*}{ Catalyst } & \multicolumn{2}{|c|}{ Crystallite size [nm] } & \multirow{2}{*}{$\begin{array}{c}\text { Total basicity } \\
{[\mu \mathrm{mol} / \mathrm{g}]}\end{array}$} & $\begin{array}{c}\text { Weak sites } \\
138-150^{\circ} \mathrm{C} \\
{[\mu \mathrm{mol} / \mathrm{g}]}\end{array}$ & $\begin{array}{c}\text { Medium sites } \\
232-251^{\circ} \mathrm{C} \\
{[\mu \mathrm{mol} / \mathrm{g}]}\end{array}$ & $\begin{array}{c}\text { Strong sites } \\
349-374^{\circ} \mathrm{C} \\
{[\mu \mathrm{mol} / \mathrm{g}]}\end{array}$ \\
\cline { 2 - 6 } Neduced & Spent & 8 & 82 & 7 & 60 & 15 \\
\hline NiLa1-HT & 9 & 8 & 55 & 21 & 30 & 4 \\
\hline NiLa2-HT & 9 & 9 & 139 & 12 & 113 & 14 \\
\hline NiLa4-HT & 9 & 10 & 122 & 21 & 87 & 14 \\
\hline
\end{tabular}

